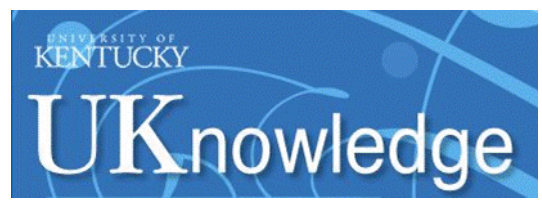

University of Kentucky

UKnowledge

\title{
A Longitudinal Study of the Reciprocal Relationship Between Ever Smoking and Urgency in Early Adolescence
}

\author{
Jessica L. Burris \\ University of Kentucky, jessica.burris@uky.edu \\ Elizabeth N. Riley \\ University of Kentucky, elizabeth.n.riley@uky.edu \\ Gabriella E. Puleo \\ University of Kentucky, gabypuleomonzon@gmail.com \\ Gregory T. Smith \\ University of Kentucky, gsmith@email.uky.edu
}

Follow this and additional works at: https://uknowledge.uky.edu/psychology_facpub

Part of the Psychology Commons, and the Substance Abuse and Addiction Commons

Right click to open a feedback form in a new tab to let us know how this document benefits you.

\section{Repository Citation}

Burris, Jessica L.; Riley, Elizabeth N.; Puleo, Gabriella E.; and Smith, Gregory T., "A Longitudinal Study of the Reciprocal Relationship Between Ever Smoking and Urgency in Early Adolescence" (2017). Psychology Faculty Publications. 171.

https://uknowledge.uky.edu/psychology_facpub/171

This Article is brought to you for free and open access by the Psychology at UKnowledge. It has been accepted for inclusion in Psychology Faculty Publications by an authorized administrator of UKnowledge. For more information, please contact UKnowledge@lsv.uky.edu. 


\section{A Longitudinal Study of the Reciprocal Relationship Between Ever Smoking and Urgency in Early Adolescence}

\section{Digital Object Identifier (DOI)}

https://doi.org/10.1016/j.drugalcdep.2017.06.007

Notes/Citation Information

Published in Drug and Alcohol Dependence, v. 178, p. 519-526.

(C) 2017 Elsevier B.V. All rights reserved.

This manuscript version is made available under the CC-BY-NC-ND 4.0 license https://creativecommons.org/licenses/by-nc-nd/4.0/.

The document available for download is the author's post-peer-review final draft of the article. 


\title{
A Longitudinal Study of the Reciprocal Relationship between Ever Smoking and Urgency in Early Adolescence
}

\author{
Jessica L. Burris ${ }^{a}$, Elizabeth Riley ${ }^{b}$, Gabriella E. Puleoc, and Gregory T. Smith ${ }^{d}$ \\ aDepartment of Psychology and Markey Cancer Center, University of Kentucky, Lexington, KY, \\ USA, University of Kentucky, 206 Combs Cancer Research Building, Lexington, KY 40536-0096, \\ USA; burris.jessica@gmail.com \\ bDepartment of Psychology, University of Kentucky, Lexington, KY, USA, University of Kentucky, \\ 171 Funkhouser Dr., Lexington, KY 40506-0044, USA; elizabeth.n.riley@uky.edu \\ 'Department of Psychology, University of Kentucky, Lexington, KY, USA, University of Kentucky, \\ 171 Funkhouser Dr., Lexington, KY 40506-0044, USA; gepu223@g.uky.edu \\ 'Department of Psychology, University of Kentucky, Lexington, KY, USA, University of Kentucky, \\ 105 Kastle Hall, Lexington, KY 40506-0044, USA; gsmith@uky.edu
}

\section{Abstract}

Background-Among early adolescents in the United States (U.S.), the prevalence of cigarette smoking is at its lowest level in recent decades. Nonetheless, given the risks of smoking in early development, it remains critically important to study both risk factors for smoking and risks from smoking. This longitudinal study with U.S. early adolescents examines smoking initiation and tests a model of reciprocal prediction between ever smoking and the personality trait of urgency (i.e., mood-based impulsivity), a trait that increases risk for multiple forms of dysfunction.

\begin{abstract}
Methods-Participants ( $n=1906$; 90\% 10-11 years old, 50\% female, 39\% racial minorities at baseline) completed questionnaires $1-2$ times per year starting in $5^{\text {th }}$ grade and ending in $9^{\text {th }}$ grade. Structural equation modeling allowed tests of bidirectional relationships between ever smoking and urgency controlling for pubertal status and negative affect at each wave.
\end{abstract}

Results-Incidence of ever smoking increased from 5\% to $27 \%$ over time, with current smoking around 5\% at the last wave. Urgency at each wave predicted ever smoking at the next wave above and beyond covariates and prior smoking (all $p<.01$ ). Likewise, with one exception, ever smoking

Correspondence to: Jessica L. Burris.

Publisher's Disclaimer: This is a PDF file of an unedited manuscript that has been accepted for publication. As a service to our customers we are providing this early version of the manuscript. The manuscript will undergo copyediting, typesetting, and review of the resulting proof before it is published in its final citable form. Please note that during the production process errors may be discovered which could affect the content, and all legal disclaimers that apply to the journal pertain.

Contributors

Each author contributed to the article in accordance with her or his authorship placement. G.T. Smith and E. Riley were jointly responsible for study conception, design, and execution as well as editing the manuscript. J.L. Burris led manuscript preparation and editing. G.E. Puleo assisted with manuscript preparation and editing. All authors have approved the final version and agree to have their names attached to it.

Conflict of Interest

No conflict declared. 
predicted an increase in urgency at the subsequent wave above and beyond covariates and prior urgency (all $p<.05)$.

Conclusion-Results show that risk for smoking increases with higher levels of urgency and urgency increases secondary to engagement in smoking. Future work should therefore explore urgency as a point of prevention for smoking and smoking cessation as a means to mitigate moodbased impulsivity.

\section{Keywords}

Adolescence; impulsivity; longitudinal design; smoking; urgency

\section{Introduction}

\subsection{U.S. Epidemiology of Smoking in Early Adolescence}

Among early adolescents (i.e., youth ages 12-14 or middle school students) in the United States (U.S.), the prevalence of cigarette smoking is at its lowest level in recent decades (Centers for Disease Control and Prevention, 2015), but the overall threat of tobacco use remains a key public health challenge. To illustrate, the prevalence of current smoking (i.e., past 30 days) dropped significantly between 2011 and 2015, with a decline from $4.3 \%$ to $2.3 \%$ among middle school students (Singh et al., 2016). However, the prevalence of current electronic cigarette use and hookah use increased significantly during this same time period, with a rise from $0.6 \%$ to $5.3 \%$ and $1.0 \%$ to $2.0 \%$, respectively (Singh et al., 2016). As a whole, recent nationwide data show no change in the overall prevalence of current tobacco use among U.S. early adolescents; the prevalence rate in 2015 was 7.4\% (Singh et al., 2016). Furthermore, the debate is ongoing as to whether or not newer, more popular tobacco products (e.g., electronic cigarettes) will function as a "gateway" to smoking and/or maintain nicotine dependence among youth smokers who might otherwise quit (Kandel and Kandel, 2014; Leventhal et al., 2015). Given this, and the known risks of smoking early in development, it remains critically important to understand risk factors for smoking onset.

\subsection{Impact of Smoking in Early Adolescence}

Most adult smokers initiated smoking very early in life, with the average age of onset occurring in early adolescence (Campaign for Tobacco-Free Kids, 2015; U.S. Department of Health and Human Services, 2012). Also noteworthy are findings that nicotine dependence can happen within days or weeks of smoking onset (Campaign for Tobacco-Free Kids, 2015; DiFranza et al., 2000; Gervais et al., 2006) and at relatively low or infrequent levels of use (Rose et al., 2010). Once dependence is established, it is very difficult to quit smoking (Bancej et al., 2007; Hughes et al., 2013; Partos et al., 2013). The deleterious effects of smoking are of course profound, and early adolescents are especially vulnerable to the potential for detrimental consequences on brain development, cardiovascular and lung health, physical maturation, and general wellbeing (Counotte et al., 2011, 2009; U.S. Department of Health and Human Services, 2014). Furthermore, smoking in early adolescence increases risk for involvement in other addictive behaviors (Kandel and Kandel, 2014; Merline et al., 2004; Moss et al., 2014) and is associated with other negative outcomes, such as depressed or anxious mood, low academic achievement, family conflict, 
and interpersonal difficulties (Fleming et al., 2002; Leventhal and Zvolensky, 2015; Morin et al., 2012; O'Loughlin et al., 2009; Windle and Windle, 2001). To date, much of the adolescent smoking research focuses on the developmental period of middle-tolate adolescence (i.e., youth ages 15-20 or high school and college students) (Bancej et al., 2007), and while important, this research cannot fully answer questions about which factors are vital to smoking initiation and maintenance in early life. Thus, there is a need to identify factors that predispose some individuals toward this particular risk behavior in early adolescence, with a focus on factors that are likely to be suitable candidates for prevention.

\subsection{Overview of Risk Factors for Smoking in Early Adolescence}

A large number of risk factors exist for smoking in adolescence, especially if one considers research that covers youth ages 12 to 20 . As a complete summary of the correlates of smoking in adolescence is beyond the scope of this article, the goal herein is to provide a summary of modifiable risk factors that may be particularly relevant in early adolescence. First, parental and other familial influence plays a role such that smoking is most likely among early adolescents who observe family members smoking (Hu et al., 2008; O'Loughlin et al., 2009). This risk is particularly strong if said family members are people with whom the adolescent is closely attached or deeply respects (Fleming et al., 2002). Second, peer influence is also at play via the independent or combined effects of perceived behavioral norms, perceived pressure to smoke, and the existence of close friends or classmates who smoke (Ali and Dwyer, 2009; Fujimoto and Valente, 2012). Third, the experience of negative affect, psychological distress, and emotion/behavior dysregulation are positively associated with smoking in studies with adolescents (Gutman et al., 2011; Hu et al., 2008). Fourth, expectancies about smoking, for instance that it will alleviate negative affect or promote positive affect, predict smoking in early adolescence (Combs et al., 2012; Guller et al., 2015; Heinz et al., 2010; Lejuez et al., 2005). Finally, the multifaceted personality trait of impulsivity (Whiteside and Lynam, 2001) functions as an independent predictor of early adolescents' smoking (Combs et al., 2012; Doran et al., 2011; Fields et al., 2009; Guller et al., 2014).

\subsection{Current Study}

This study focuses on the last risk factor noted above: impulsivity. Since personality is only moderately stable in childhood and adolescence (Hampson and Goldberg, 2006; Hart et al., 2003), there exists the possibility that personality can be influenced by other factors, including behavior. Likewise, it is known that behavior can be influenced by personality (Elkins et al., 2006; Paunonen, 2003; Pederson et al., 2005). Ultimately, this could give rise a reciprocal relationship between behavior and personality - or as is the focus here, a reciprocal relationship between smoking and the facet of impulsivity known as "urgency." In contrast to other facets of impulsivity, such as low conscientiousness or sensation seeking, urgency refers to rash action in response to intense positive or negative emotion (Cyders \& Smith, 2007; Smith \& Cyders, 2016). This theoretical distinction is borne out by very modest correlations between urgency and other impulsigenic traits (Cyders \& Smith, 2007). As adolescents are not yet fully adept at self-regulation of behavior or emotion (Casey and Caudle, 2013; Eisenberg et al., 2011), there exists the possibility of a particularly strong link between urgency and addictive or risky behavior during this critical developmental period 
(Smith \& Cyders, 2016). In support of this premise, urgency is proven to predict the early onset of, and increased engagement in, drinking, gambling, binge eating, non-suicidal selfinjury, and of particular relevance here, smoking (Smith \& Cyders, 2016).

Despite all of the above, there is a dearth of literature that addresses the reciprocal, longitudinal relationship between smoking and urgency (or any other facet of impulsivity) in early adolescence (for an exception, see (Malmberg et al., 2013)). To address this gap in the literature, the current study of a large sample of U.S. early adolescents spans multiple years of observation to test a conceptual model whereby smoking predicts urgency and vice versa across time. Two hypotheses capture the longitudinal relationship under investigation: 1) prior engagement in smoking will predict an increase in urgency at a later date and 2) higher scores on urgency will predict a higher likelihood of ever smoking at a later date.

\section{Material and Methods}

\subsection{Sample}

Participants were 1906 early adolescents who were drawn from 23 public elementary schools across two school systems in urban, suburban, and rural areas in the southeast U.S. The sample was equally split between girls and boys. At study onset, most participants were 10 or 11 years old (22.8\% and $66.8 \%$, respectively); the full age range was 9 to 13 years old. The racial and ethnic breakdown was 60.9\% European American, 18.7\% African American, $8.2 \%$ Hispanic, $3.4 \%$ Asian American, and $8.8 \%$ other.

\subsection{Procedure}

All procedures were approved by the authors' IRB and participating school systems. A passive-consent procedure was used such that each family of a student in the $5^{\text {th }}$ grade classrooms was mailed a letter describing the study and asked to respond (via phone or mail) if they did not want their child to participate in the study. Reasons for non-participation included declination of consent from parents, declination of assent from adolescents, and language or cognitive difficulties. Participants were administered questionnaires on eight occasions: spring of $5^{\text {th }}$ grade (wave 1: 2009), fall and spring of $6^{\text {th }}, 7^{\text {th }}$, and 8 th grade (waves 2 through 7), and spring of $9^{\text {th }}$ grade (wave 8: 2013). As students progressed through their education, questionnaire administration occurred first in 23 elementary schools at wave 1 , then in 15 middle schools at waves $2-7$, and finally in 7 high schools at wave 8 .

At each wave, study staff administered questionnaires, which took 60 minutes or less to complete, in classrooms or a central location (e.g., cafeteria) during school hours.

Participants who left the participating school systems were asked to continue with the study. Those who continued did so either by completing questionnaires via mail or a secure web site. Retention from wave-to-wave ranged from $94.2 \%$ to $98.3 \%$, with $75 \%$ retention across the eight waves. Retained and not retained participants did not differ significantly on any study variable. This allowed imputation of missing data via the expectation maximization procedure (Little, 1989), which enabled use of the full sample of 1,906. 


\subsection{Measures}

2.3.1 Smoking - Participants responded to a question about how often they smoked cigarettes using a scale where $0=\mathrm{I}$ have never smoked and 5=I smoke almost daily or every day. Participants were classified as "smoking" if they smoked at least one cigarette in their life (i.e., ever smoking). Numerous other studies with children and adolescents have used similar measures with proven reliability and validity (Chassin et al., 2000; Pang et al., 2014a; Vanderveen et al., 2013).

\subsubsection{Urgency-The UPPS-R-Child Version Positive Urgency and Negative Urgency} Scales each consist of eight items with response options on a four-point Likert scale where $1=$ not at all like me and 4=very much like me (Whiteside and Lynam, 2001; Zapolski et al., 2010). Scoring involves an average of the items within each scale. A sample item for positive and negative urgency are "When I am very happy, I tend to do things that may cause problems in my life" and "When I am upset, I often act without thinking," respectively. At wave 1 , internal consistency was $a=.89$ for positive urgency and $a=.85$ for negative urgency; internal consistency was higher for both scales in later waves. The scales were highly correlated at wave 1 ( $r=.63, p<.001)$, with higher correlations in subsequent waves. Furthermore, the two scales functioned similarly in the longitudinal predictive models. As prior work also suggests positive and negative urgency are facets of a single personality trait (Cyders et al., 2007; Smith and Cyders, 2016), the positive and negative urgency scales were combined (consequently, scores range from 2-8) and subsequently treated as a unitary construct in the current study ( $a=.91$ at wave 1 , with higher values at subsequent waves).

2.3.3 Covariates-Early adolescents' smoking is correlated with many different variables, two of which were selected as covariates in this study. First, puberty is included as a covariate because a large body of evidence suggests early pubertal onset increases the likelihood of substance use and risk taking (Guller et al., 2015; Gunn and Smith, 2010). Second, negative affect is included as a covariate because of the strong link between psychological distress and smoking initiation and persistence (Cosci et al., 2011; Kassel et al., 2003).

The Pubertal Development Scale (PDS (Petersen et al., 1988)), which has strong reliability and validity (Brooks-Gunn et al., 1987; Coleman and Coleman, 2002), assessed puberty. It consists of five questions for both boys (e.g., "Do you have facial hair yet?") and girls (e.g., "Have you begun to have your period?"). Participants responded to each question on a 4point scale where $1=$ No and $4=$ Yes, a lot. Mean item scores greater than 2.5 were indicative of pubertal onset consistent with a dichotomous classification procedure (Culbert et al., 2009).

Negative affect was assessed with the Positive and Negative Affect Schedule - Child Version (PANAS-C (Laurent et al., 1999)), which includes a list of 15 negative feelings and emotions (e.g., jittery, ashamed, blue). On each item, participants indicated the extent to which they generally felt that way on a scale from $1=$ very slightly to $5=$ extremely. Scoring for the PANAS-C involves calculating the mean score across all items. Internal consistency was $a=$. 90 at wave 1 and slightly higher in subsequent waves.

Drug Alcohol Depend. Author manuscript; available in PMC 2018 September 01. 


\subsection{Data Analysis}

Structural equation modeling (SEM) was used to test the model of reciprocal influence between smoking and urgency, a process that involved proceeding through a series of model tests. Each model allowed for cross-sectional correlations between all variables or disturbance terms. Due to concerns about low base rates of smoking in the early waves resulting in misspecifications of model parameters and/or limiting the predictive power of the model from a statistical estimation standpoint, model tests were only done once the prevalence of ever smoking reached $10 \%$. Notably, because we measured lifetime point prevalence of smoking, the percentage of participants classified as "smoking" could only increase over time.

The first or baseline model (Model 1) specified autoregressive predictions within smoking, urgency, puberty, and negative affect (e.g., urgency at a given wave predicts urgency at the next wave). The second model (Model 2) involved the prediction of smoking. In addition to the paths included in the first model, there existed predictive pathways from urgency, puberty, and negative affect at a given wave to smoking the next wave. This model tested the degree to which urgency scores at each wave predicted subsequent increases in the likelihood of reporting ever smoking at the next wave, above and beyond the important covariates of autoregressive prediction, puberty, and negative affect. The third model (Model 3) built upon the second and included prediction from smoking at each wave to urgency at the next wave. To provide a rigorous test of whether smoking predicted a change in urgency over each wave-to-wave interval, puberty and negative affect were included as predictors of urgency, as were the autoregressive predictions. This sequence of models was tested with Mplus (Muthen and Muthen, 2004) using the MLR estimation method.

Improved model fit from one model to the next was assessed by the values of the Akaike information criterion (AIC) and Bayesian information criterion (BIC), both of which measure the relative quality of each statistical model for a given set of data relative to each of the other models. Both the AIC and the BIC represent criterion for model selection among a finite set of models, and the model with the lowest AIC and BIC values is preferred.

\section{Results}

\subsection{Summary of Smoking and Urgency Over Time}

Table 1 presents descriptive statistics on smoking, urgency, puberty, and negative affect and Table 2 presents a correlation matrix for these same variables. As Table 1 shows, the prevalence of ever smoking increased from $5.2 \%$ at wave 1 (spring of $5^{\text {th }}$ grade) to $27.1 \%$ at wave 8 (spring of $9^{\text {th }}$ grade). The prevalence of ever smoking first exceeded $10 \%$ at wave 4 (fall of $7^{\text {th }}$ grade), so the predictive models described below span waves 4 to 8 . Mean scores in urgency ranged from a low of 4.15 (standard deviation, $\mathrm{SD}=1.33$ ) at wave 2 to a high of $4.35(\mathrm{SD}=1.30)$ at wave 1 . Concerning the overall stability of the trait of urgency, across each wave-to-wave interval, the median correlation of urgency scores at adjacent waves was $r=.65$ (range: .58-.70). 


\subsection{Models of Reciprocal Prediction between Ever Smoking and Urgency}

In Model 1, all autoregressive pathways within ever smoking, urgency, puberty, and negative affect between waves were significant $(p<.05)$. Thus, prior behavior was highly predictive of future behavior (smoking) and prior personality was highly predictive of later personality (urgency).

In Model 2, urgency at each wave independently predicted the likelihood of ever smoking the following wave (all $p<.01$ ). In addition, pubertal status independently predicted subsequent classification of ever smoking in all cases (all $p<.01$ ). Finally, negative affect at waves 5 and 7 predicted ever smoking at their respective subsequent waves independent of the other predictors $(p<.01)$. Model 2 fit the data better than the baseline model: Model 1's $\mathrm{AIC}=69363.55$ and $\mathrm{BIC}=69796.34$ versus Model 2's $\mathrm{AIC}=67104.93$ and $\mathrm{BIC}=67670.88$.

In Model 3, the classification of ever smoking at a given wave independently predicted urgency at the next wave in all cases but one (all $p<.05$ ). Urgency was also predicted by pubertal status at the first wave, and by negative affect in all cases (all $p<.05$ ); data not shown in Figure 1 for model simplicity. Model 3, which involved reciprocal prediction between ever smoking and urgency, fit the data better than did either of the previous models: Model 3's AIC $=67048.53$ and BIC $=67681.06$. Figure 1 presents this final model where the magnitude of the unique predictive effects from ever smoking to and from urgency is reflected in unstandardized coefficients.

\section{Discussion}

Tobacco use prevention among U.S. children and adolescents is an important public health goal, and recent nationwide and other population-based data show remarkable progress in this area (Centers for Disease Control and Prevention, 2015). As fewer than 5\% of $9^{\text {th }}$ graders in this study reported current smoking, the findings related to the prevalence of smoking among U.S. early adolescents complements those of prior work (Singh et al., 2016) and underscores the overall success of U.S. tobacco control efforts (Backinger et al., 2003; Lantz et al., 2000). However, a closer look at study data suggest it is too soon to celebrate. This is because the prevalence of current smoking rose steadily from $5^{\text {th }}$ grade $(0.7 \%)$ to $9^{\text {th }}$ grade $(4.0 \%)$, as did the prevalence of ever smoking (5.2\% to $27.1 \%$, respectively). It thus seems that early adolescence remains a critical developmental period in which a sizeable percentage of youth will experiment with smoking.

Research that aims to better understand which individuals will versus will not initiate smoking, whether it occur in adolescence (García-Rodríguez et al., 2014;

Mohammadpoorasl et al., 2010) or in young adulthood (Doran et al., 2013; O'Loughlin et al., 2014), remains of paramount importance. The personality trait of urgency (Cyders et al., 2007; Smith and Cyders, 2016) holds promise as one key explanatory variable for smoking initiation (Combs et al., 2012; Guller et al., 2014). In this study the relationship was quite strong, as all bivariate correlations between ever smoking and urgency were significant, despite ever smoking being a low base rate outcome in early waves. Moreover, SEM provided a means to explore urgency's independent and longitudinal effect on ever smoking after controlling for other important variables (including prior smoking status), the results of

Drug Alcohol Depend. Author manuscript; available in PMC 2018 September 01. 
which further highlight urgency's predictive utility. Indeed, the greater the tendency to act rashly in response to strong emotions, the greater the chance of smoking in the future. This finding is important and compliments some prior longitudinal work (Guller et al., 2014; Zapolski et al., 2010).

What is particularly noteworthy about this study, however, is the examination of the predictive pathway from ever smoking to personality. Here, classification of ever smoking at one wave was a significant predictor of urgency at the next wave on three of four occasions. These findings raise the possibility that smoking leads to personality change, which in turn, increases the odds of smoking in the future. In other words, study findings support a longitudinal model whereby smoking and urgency are reciprocally related in early adolescence. Further, because urgency increases risk transdiagnostically (Wills et al., 2001), the downstream effects of early adolescent smoking may extend to behaviors and problems beyond those associated with smoking.

To the authors' knowledge, this is one of the first longitudinal tests of a bidirectional relationship between smoking and urgency (or any other facet of impulsivity) in children, adolescents, or young adults despite a sizeable body of cross-sectional work that demonstrates a positive link between the two variables (Dir et al., 2016; Pang et al., 2014b; Settles et al., 2012). Notably, the results converge with those of Malmberg and colleagues (2013) who found a longitudinal, reciprocal relationship between smoking history and impulsivity in a large sample of Dutch adolescents (Malmberg et al., 2013). The mechanisms at play were not under investigation here or in the aforesaid study, but some comments on the topic are warranted. Urgency is readily understood as the tendency to act hastily in the face of strong positive and/or negative affective states, and smoking is generally believed to induce positive affect and/or alleviate negative affect (Heinz et al., 2010). To the extent that adolescents high in urgency hold strong expectancies about the positive and negative reinforcement properties of smoking, they might be predisposed to smoke when in positive and negative moods, respectively, which then bolsters their expectancies about the benefits of smoking for affect/mood enhancement. A feedback loop could therefore arise such that there is a meditational pathway between urgency and smoking through smoking expectancies. This process, known as the acquired preparedness model of risk, has been demonstrated in relation to young adults' smoking (Doran et al., 2013). As for the reverse association, that is, the influence of smoking on urgency, it is well documented that nicotine and other substance use can alter neurobiology and neurocognitive function in a way that ultimately makes individuals more susceptible to behavioral disinhibition and other indicators of impulsive personality (Bloom et al., 2014; de Wit, 2009). Thus in the absence of intervention, the link between smoking and urgency may strengthen over time.

The current results plus those from similar cross-sectional work (Pang et al., 2014b; Settles et al., 2012) suggest prevention strategies for smoking in early adolescence should include, or even prioritize, efforts to reduce urgency. Urgency can be viewed as a consequence of self-control deficits, and self-control problems in childhood significantly increase the likelihood of smoking in adulthood, an effect that is largely mediated by smoking in adolescence (Daly et al., 2016). Thus one viable strategy for smoking prevention is training children and adolescents in self-control (Diamond, 2012; Eisenberg et al., 2011), an 
intervention that is efficacious for smoking reduction and cessation in adulthood (Muraven, 2010; Oaten and Cheng, 2006). Self-control training might be especially fitting for children and adolescents high in urgency because it is in emotional contexts (i.e., "hot" situations) that adolescents' ability to execute self-control is most taxed (Casey and Caudle, 2013), and the manner in which children and adolescents respond to "hot situations" may have significant bearing on the likelihood of their smoking. Given this, it is encouraging that at least one self-control training program demonstrates positive effects for prevention of adolescents' substance use (Botvin and Griffin, 2002) and another skills training program produces reductions in adolescents' level of urgency and disruptive behavior (Zapolski and Smith, 2016).

The results of this study must be viewed in light of its limitations. First, study design and data collection occurred prior to the sharp rise in the widespread distribution and subsequent uptake of electronic cigarettes and other "alternative tobacco products"; consequently, participants' use of these products was not assessed. It would therefore be inadvisable to draw any firm conclusions on the nature of the relationship between urgency and tobacco use other than cigarette smoking on the basis of this study alone. That said, there is no reason to believe the observed reciprocal relationship observed would not extend to other forms of tobacco use. Second, this study focused on ever smoking as opposed to current smoking. This was largely a function of the study design/sample, as not surprisingly, there was not a high prevalence of current smoking in early adolescence. That said, there is evidence that different mechanisms are at play in the transition from never use to first use (akin to ever smoking) and from first use to regular use (akin to current smoking) (GarcíaRodríguez et al., 2014; Mohammadpoorasl et al., 2010), which raises the possibility that urgency's relationship with smoking may differ dependent upon the precise outcome of interest. Third, this study did not consider other substance use outcomes (e.g., alcohol use) albeit known that many adolescents are poly-users (Moss et al., 2014). Fourth, as the analyses controlled for negative affect, it is unknown to what extent the strength of the relationship between ever smoking and urgency might be moderated by negative affect. Finally, while this study was conducted with a racially and ethnically diverse sample that included an even split of boys and girls, the geographic composition of the sample is limited to one region of the U.S., and it possible the results do not generalize well to the entire country.

It is frequently said the best predictor of future behavior is past behavior, and while this maxim is not without qualification, in the case of smoking, some data supports the stability of behavior over time (Daly et al., 2016; Paul et al., 2008). What this study adds to the literature is evidence to suggest a facet of impulsivity-namely urgency-partly underlies the behavior of smoking, and contributes to its emergence in early development. Thus, it may be the stability of urgency (and its interaction with smoking) that gives rise to the apparent stability in smoking. For this reason, the personality trait of urgency should be considered as a point of prevention for smoking, and given current evidence to support a reciprocal relationship, smoking cessation should therefore be considered as a point of prevention and intervention for urgency, potentially reducing risk transdiagnostically. 


\section{Acknowledgments}

\section{Role of Funding Source}

This work was supported by the National Institutes of Health (grant numbers R01 AA016166 from the National Institute on Alcohol Abuse and Alcoholism to G.T. Smith and K07 CA181351 from the National Cancer Institute to J.L. Burris). Its content is solely the responsibility of the authors and does not necessarily represent the official views of. The National Institutes of Health had no role in study design; in the collection, analysis, and interpretation of data; in writing of the report; and in the decision to submit the article for publication.

\section{References}

Ali MM, Dwyer DS. Estimating peer effects in adolescent smoking behavior: A longitudinal analysis. J. Adolesc. Heal. 2009; 45:402-408. DOI: 10.1016/j.jadohealth.2009.02.004

Backinger CL, Fagan P, Matthews E, Grana R. Adolescent and young adult tobacco prevention and cessation: current status and future directions. Tob. Control. 2003; 12(Suppl I):i46-i53. DOI: 10.1136/tc.12.suppl_4.iv46

Bancej C, O’Loughlin J, Platt RW, Paradis G, Gervais A. Smoking cessation attempts among adolescent smokers: A systematic review of prevalence studies. Tob. Control. 2007; 16:e8.doi: 10.1136/tc.2006.018853 [PubMed: 18048598]

Bloom EL, Matsko SV, Cimino CR. The relationship between cigarette smoking and impulsivity: A review of personality, behavioral, and neurobiological assessment. Addict. Res. Theory. 2014; 22:386-397. DOI: 10.3109/16066359.2013.867432

Botvin GJ, Griffin KW. Life skills training as a primary prevention approach for adolescent drug abuse and other problem behaviors. Int. J. Emerg. Ment. Health. 2002; 4:41-47. [PubMed: 12014292]

Brooks-Gunn J, Warren MP, Rosso J, Gargiulo J. Validity of self-report measures of girls' pubertal status. Child Dev. 1987; 58:829-841. DOI: 10.2307/1130220 [PubMed: 3608653]

Campaign for Tobacco-Free Kids. [accessed 6.20.16] The path to tobacco addiction starts at very young ages [WWW Document]. 2015. URL https://www.tobaccofreekids.org/research/ factsheets/pdf/0127.pdf

Casey BJ, Caudle K. The teenage brain: Self control. Curr. Dir. Psychol. Sci. 2013; 22:82-87. DOI: 10.1177/0963721413480170 [PubMed: 25284961]

Centers for Disease Control and Prevention. [accessed 6.6.16] Current cigarette smoking among U.S. high school students lowest in 22 years [WWW Document]. 2015. URL http://www.cdc.gov/media/ releases/2014/p0612-yrbs.html

Chassin L, Presson CC, Pitts SC, Sherman SJ. The natural history of cigarette smoking from adolescence to adulthood in a midwestern community sample: Multiple trajectories and their psychosocial correlates. Heal. Psychol. 2000; 19:223-231.

Coleman L, Coleman J. The measurement of puberty: A review. J. Adolesc. 2002; 25:535-550. DOI: 10.1006/jado.2002.0494 [PubMed: 12234559]

Combs JL, Spillane NS, Caudill L, Stark B, Smith GT. The acquired preparedness risk model applied to smoking in 5th grade children. Addict. Behav. 2012; 37:331-334. DOI: 10.1016/j.addbeh. 2011.11.005 [PubMed: 22143003]

Cosci F, Pistelli F, Lazzarini N, Carrozzi L. Nicotine dependence and psychological distress: Outcomes and clinical implications in smoking cessation. Psychol. Res. Behav. Manag. 2011; 4:119-128. DOI: 10.2147/PRBM.S14243 [PubMed: 22114542]

Counotte DS, Goriounova NA, Li KW, Loos M, Van der Schors RC, Schetters D, Schoffelmeer AN, Smit AB, Mansvelder HD, Pattij T, Spijker S. Lasting synaptic changes underlie attention deficits caused by nicotine exposure during adolescence. Nat. Neurosci. 2011; 14:417-419. DOI: 10.1038/nn.2770 [PubMed: 21336271]

Counotte DS, Spijker S, Van de Burgwal LH, Hogenboom F, Schoffelmeer AN, De Vries TJ, Smit AB, Pattij T. Long-lasting cognitive deficits resulting from adolescent nicotine exposure in rats. Neuropsychopharmcology. 2009; 34:299-306. DOI: 10.1038/npp.2008.96

Culbert K, Burt SA, McGue M, Iacono WG, Klump KL. Puberty and the genetic diathesis of disordered eating attitudes and behaviors. J. Abnorm. Psychol. 2009; doi: 10.1037/a0017207 
Cyders MA, Smith GT, Spillane NS, Fischer S, Annus AM, Peterson C. Integration of impulsivity and positive mood to predict risky behavior: Development and validation of a measure of positive urgency. Psychol. Assess. 2007; 19:107-118. DOI: 10.1037/1040-3590.19.1.107 [PubMed: 17371126]

Daly M, Egan M, Quigley J, Delaney L, Baumeister R. Childhood Self-control predicts smoking throughout life: Evidence from 21,000 cohort study participants. Heal. Psychol. 2016; Advance on. doi: $10.1037 /$ hea0000393

de Wit H. Impulsivity as a determinant and consequence of drug use: A review of underlying processes. Addict. Biol. 2009; 14:22-31. DOI: 10.1111/j.1369-1600.2008.00129.x [PubMed: 18855805]

Diamond A. Activities and programs that improve children's executive functions. Curr. Dir. Psychol. Sci. 2012; 21:335-341. DOI: 10.1177/0963721412453722 [PubMed: 25328287]

DiFranza JR, Rigotti NA, McNeill AD, Ockene JK, Savageau J, St Cyr D, Coleman M. Initial symptoms of nicotine dependence in adolescents. Tob. Control. 2000; 9:313-319. DOI: 10.1136/tc.9.3.313 [PubMed: 10982576]

Dir AL, Banks DE, Zapolski TCB, McIntyre E, Hulvershorn LA. Negative urgency and emotion regulation predict positive smoking expectancies in non-smoking youth. Addict. Behav. 2016; 58:47-52. DOI: 10.1016/j.addbeh.2016.02.014 [PubMed: 26905764]

Doran N, Khoddam R, Sanders PE, Schweizer CA, Trim RS, Myers MG. A prospective study of the Acquired Preparedness Model: The effects of impulsivity and expectancies on smoking initiation in college students. Psychol. Addict. Behav. 2013; :714-722. DOI: 10.1037/a0028988 [PubMed: 22686965]

Doran N, Sanders PE, Bekman NM, Worley MJ, Monreal TK, McGee E, Cummins K, Brown SA. Mediating influences of negative affect and risk perception on the relationship between sensation seeking and adolescent cigarette smoking. Nicotine Tob. Res. 2011; 13:457-465. DOI: 10.1093/ntr/ntr025 [PubMed: 21436297]

Eisenberg N, Spinrad TL, Eggum ND. Emotion-related self-regulation and its relation to children's maladjustment. Annu. Rev. Clin. Psychol. 2011; 6:495-525. DOI: 10.1146/annurev.clinpsy. 121208.131208.Emotion-Related

Elkins IJ, King SM, McGue M, Iacono WG. Personality traits and the development of nicotine, alcohol, and illicit drug disorders: Prospective links from adolescence to young adulthood. J. Abnorm. Psychol. 2006; 115:26-39. DOI: 10.1037/0021-843X.115.1.26 [PubMed: 16492093]

Fields S, Collins C, Lerras K, Reynolds B. Dimensions of impulsive behavior in adolescent smokers and nonsmokers. Exp. Clin. Psychopharmacol. 2009; 17:302-311. DOI: 10.1037/ a0017185.Dimensions [PubMed: 19803629]

Fleming CB, Kim H, Harachi TW, Catalano RF. Family processes for children in early elementary school as predictors of smoking initiation. J. Adolesc. Heal. 2002; 30:184-189. DOI: 10.1016/ S1054-139X(01)00327-5

Fujimoto K, Valente TW. Decomposing the components of friendship and friends' influence on adolescent drinking and smoking. J. Adolesc. Heal. 2012; 51:136-143. DOI: 10.1016/j.jadohealth. 2011.11.013

García-Rodríguez O, Blanco C, Wall MM, Wang S, Jin CJ, Kendlerc KS. Toward a comprehensive developmental model of smoking initiation and nicotine dependence. Drug Alcohol Depend. 2014; 144:160-169. DOI: 10.1016/j.drugalcdep.2014.09.002 [PubMed: 25262528]

Gervais A, O'Loughlin J, Meshefedjian G, Bancej C, Tremblay M. Milestones in the natural course of onset of cigarette use among adolescents. Can. Med. Assoc. J. 2006; 175:255-261. DOI: 10.1503/ cmaj.051235 [PubMed: 16880445]

Guller L, Zapolski TC, Smith GT. Longitudinal test of a reciprocal model of smoking expectancies and smoking experience in youth. Psychol. Addict. Behav. 2015; 29:201-210. DOI: 10.1037/ adb0000002 [PubMed: 25180556]

Guller L, Zapolski TCB, Smith GT. Personality measured in elementary school predicts middle school addictive behavior involvement. J. Psychopathol. Behav. Assess. 2014; 37:523-532. DOI: 10.1007/ s10862-014-9474-6 
Gunn RL, Smith G. Risk factors for elementary school drinking: Pubertal status, personality, and alcohol expectancies concurrently predict 5th grade alcohol consumption. Psychol. Addict. Behav. 2010; 24:617-627. DOI: 10.1037/a0020334.Risk [PubMed: 20822192]

Gutman LM, Eccles JS, Peck S, Malanchuk O. The influence of family relations on trajectories of cigarette and alcohol use from early to late adolescence. J. Adolesc. 2011; 34:119-128. DOI: 10.1016/j.adolescence.2010.01.005 [PubMed: 20129658]

Hampson SE, Goldberg LR. A first large cohort study of personality trait stability over the 40 years between elementary school and midlife. J. Pers. Soc. Psychol. 2006; 91:763-779. DOI: 10.1037/0022-3514.91.4.763 [PubMed: 17014298]

Hart D, Atkins R, Fegley SG. Personality and development in childhood: A person-centered approach. Monogr. Soc. Res. Child Dev. 2003; 68

Heinz AJ, Kassel JD, Berbaum M, Mermelstein R. Adolescents' expectancies for smoking to regulate affect predict smoking behavior and nicotine dependence over time. Drug Alcohol Depend. 2010; 111:128-135. DOI: 10.1016/j.drugalcdep.2010.04.001 [PubMed: 20547013]

Hu M-C, Muthen B, Schaffran C, Griesler PC, Kandel DB. Developmental trajectories of criteria of nicotine dependence in adolescence. Drug Alcohol Depend. 2008; 98:94-104. DOI: 10.1016/ j.drugalcdep.2008.04.017 [PubMed: 18602225]

Hughes JR, Solomon LJ, Fingar JR, Naud S, Helzer JE, Callas PW. The natural history of efforts to stop smoking: A prospective cohort study. Drug Alcohol Depend. 2013; 128:171-174. DOI: 10.1016/j.drugalcdep.2012.08.010 [PubMed: 22939878]

Kandel ER, Kandel DB. A molecular basis for nicotine as a gateway drug. N. Engl. J. Med. 2014; 371:932-943. DOI: 10.1056/NEJMsa1405092 [PubMed: 25184865]

Kassel JD, Stroud LR, Paronis CA. Smoking, stress, and negative affect: Correlation, causation, and context across stages of smoking. Psychol. Bull. 2003; 129:270-304. DOI: 10.1037/0033-2909.129.2.270 [PubMed: 12696841]

Lantz PM, Jacobson PD, Warner KE, Wasserman JV, Pollack HA, Berson J, Ahlstrom A, Monica S. Investing in youth tobacco control: A review of smoking prevention and control strategies. Tob. Control. 2000; 9:47-63. DOI: 10.1136/tc.9.1.47 [PubMed: 10691758]

Laurent J, Catanzaro S, Joiner T Jr, Rudolph K, Potter K, Lambert S, Osborne L, Gathright T. A measure of positive and negative affect for children: Scale development and preliminary validation. Psychol. Assess. 1999; 11:326-338. DOI: 10.1037/1040-3590.11.3.326

Lejuez CW, Aklin W, Bornovalova MA, Moolchan ET. Differences in risk-taking propensity across inner-city adolescent ever- and never-smokers. Nicotine Tob. Res. 2005; 7:71-79. DOI: 10.1080/146222004123313284 [PubMed: 15804679]

Leventhal AM, Strong DR, Kirkpatrick MG, Unger JB, Sussman S, Riggs NR, Stone MD, Khoddam R, Samet JM, Audrain-McGovern J. Association of electronic cigarette use with initiation of combustible tobacco product smoking in early adolescence. J. Am. Med. Assoc. 2015; 314:700.doi: 10.1001/jama.2015.8950

Leventhal AM, Zvolensky MJ. Anxiety, depression, and cigarette smoking: A transdiagnostic vulnerability framework to understanding emotion-smoking comorbidity. Psychol. Bull. 2015; doi: $10.1037 /$ bul0000003

Little R. The analysis of social science data with missing values. Sociol. Methods Res. 1989; 18:292326. DOI: $10.1177 / 0049124189018002004$

Malmberg M, Kleinjan M, Overbeek G, Vermulst AA, Lammers J, Engels RCME. Are there reciprocal relationships between substance use risk personality profiles and alcohol or tobacco use in early adolescence? Addict. Behav. 2013; 38:2851-2859. DOI: 10.1016/j.addbeh.2013.08.003 [PubMed: 24018230]

Merline AC, O’Malley PM, Schulenberg JE, Bachman JG, Johnston LD. Substance use among adults 35 years of age: Prevalence, adulthood predictors, and impact of adolescent substance use. Am. J. Public Health. 2004; 94:96-102. DOI: 10.2105/AJPH.94.1.96 [PubMed: 14713705]

Mohammadpoorasl A, Fakhari A, Rostami F, Shamsipour M, Hamideh R, Goreishizadeh MA. Predictors of transition in different stages of smoking: A longitudinal study. Addict. Heal. 2010; 2:49-56. 
Morin AJS, Rodriguez D, Fallu J-S, Maïano C, Janosz M. Academic achievement and smoking initiation in adolescence: A general growth mixture analysis. Addiction. 2012; 107:819-828. DOI: 10.1111/j.1360-0443.2011.03725.x [PubMed: 22098175]

Moss HB, Chen CM, Yi H. Early adolescent patterns of alcohol, cigarettes, and marijuana polysubstance use and young adult substance use outcomes in a nationally representative sample. Drug Alcohol Depend. 2014; 136:51-62. DOI: 10.1016/j.drugalcdep.2013.12.011 [PubMed: 24434016]

Muraven M. Practicing self-control lowers the risk of smoking lapse. Psychol. Addict. Behav. 2010; 24:446-252. DOI: 10.1037/a0018545 [PubMed: 20853930]

Muthen, L., Muthen, B. MPlus: the Comprehensive modeling program for applied researchers, Users' guide. 3. Muthen \& Muthen; Los Angeles, CA: 2004.

O'Loughlin J, Karp I, Koulis T, Paradis G, Difranza J. Determinants of first puff and daily cigarette smoking in adolescents. Am. J. Epidemiol. 2009; 170:585-597. DOI: 10.1093/aje/kwp179 [PubMed: 19635735]

O’Loughlin JL, Dugas EN, O’Loughlin EK, Karp I, Sylvestre MP. Incidence and determinants of cigarette smoking initiation in young adults. J Adolesc Health. 2014; 54:26-32. DOI: 10.1016/ j.jadohealth.2013.07.009 [PubMed: 23992758]

Oaten M, Cheng K. Improved self-control: The benefits of a regular program of academic study. Basic Appl. Soc. Psych. 2006; 28:1-16. DOI: 10.1207/s15324834basp2801_1

Pang RD, Farrahi L, Glazier S, Sussman S, Leventhal AM. Depressive symptoms, negative urgency and substance use initiation in adolescents. Drug Alcohol Depend. 2014a; 144:225-30. DOI: 10.1016/j.drugalcdep.2014.09.771 [PubMed: 25280962]

Pang RD, Hom MS, Geary BA, Doran N, Spillane NS, Guillot CR, Leventhal AM. Relationships between trait urgency, smoking reinforcement expectancies, and nicotine dependence. J. Addict. Dis. 2014b; 33:83-93. DOI: 10.1080/10550887.2014.909695 [PubMed: 24784229]

Partos TR, Borland R, Yong H-H, Hyland A, Cummings KM. The quitting rollercoaster: How recent quitting history affects future cessation outcomes (data from the International Tobacco Control 4country cohort study). Nicotine Tob. Res. 2013; 15:1578-1587. DOI: 10.1093/ntr/ntt025 [PubMed: 23493370]

Paul SL, Blizzard L, Patton GC, Dwyer T, Venn A. Parental smoking and smoking experimentation in childhood increase the risk of being a smoker 20 years later: the Childhood Determinants of Adult Health Study. Addiction. 2008; 103:846-853. DOI: 10.1111/j.1360-0443.2008.02196.x [PubMed: 18412765]

Paunonen SV. Big Five factors of personality and replicated predictions of behavior. J. Pers. Soc. Psychol. 2003; 84:411-424. DOI: 10.1037/0022-3514.84.2.411 [PubMed: 12585813]

Pederson AK, King JE, Landau VI. Chimpanzee (Pan troglodytes) personality predicts behavior. J. Res. Pers. 2005; 39:534-549. DOI: 10.1016/j.jrp.2004.07.002

Petersen AC, Crockett L, Richards M, Boxer A. A self-report measure of pubertal status: Reliability, validity, and initial norms. J. Youth Adolesc. 1988; 17:117-133. DOI: 10.1007/BF01537962 [PubMed: 24277579]

Rose JS, Dierker LC, Donny E. Nicotine dependence symptoms among recent onset adolescent smokers. Drug Alcohol Depend. 2010; 106:126-132. DOI: 10.1016/j.drugalcdep.2009.08.012 [PubMed: 19765916]

Settles RE, Fischer S, Cyders MA, Combs JL, Gunn RL, Smith GT. Negative urgency: A personality predictor of externalizing behavior characterized by neuroticism, low conscientiousness, and disagreeableness. J. Abnorm. Psychol. 2012; 121:160-172. DOI: 10.1037/a0024948 [PubMed: 21859164]

Singh T, Arrazola RA, Gorey CG, Husten CG, Neff LJ, Homa DM, King BA. Tobacco use among middle and high school students — United States, 2011-2015. Morb. Mortal. Wkly. Rep. 2016; 65:361-367. DOI: 10.15585/mmwr.mm6514a1

Smith GT, Cyders MA. Integrating affect and impulsivity: The role of positive and negative urgency in substance use risk. Drug Alcohol Depend. 2016; 163(Supple):S3-S12. DOI: 10.1016/j.drugalcdep. 2015.08.038 [PubMed: 27306729] 
U.S. Department of Health and Human Services. The health consequences of smoking- 50 years of progress: A report of the Surgeon General. Atlanta: 2014.

U.S. Department of Health and Human Services. Preventing tobacco use among youth and young adults: A report of the Surgeon General. Atlanta: 2012.

Vanderveen J, Cohen L, Watson N. Utilizing a multimodal assessment strategy to examine variations of impulsivity among young adults engaged in co-occurring smoking and binge drinking behaviors. Drug Alcohol Depend. 2013; 127:150-155. DOI: 10.1016/j.drugalcdep.2012.06.026 [PubMed: 22818514]

Whiteside S, Lynam D. The Five Factor Model and impulsivity: using a structural model of personality to understand impulsivity. Pers. Individ. Dif. 2001; 30:669-689. DOI: 10.1016/ S0191-8869(00)00064-7

Willls TA, Sandy JM, Yaeger AM, Cleary SD, Shinar O. Coping dimensions, life stress, and adolescent substance use: A latent growth analysis. J. Abnorm. Psychol. 2001; 110:309-323. [PubMed: 11358025]

Windle M, Windle RC. Depressive symptoms and cigarette smoking among middle adolescents: Prospective associations and intrapersonal and interpersonal influences. J. Consult. Clin. Psychol. 2001; 69:215-216. DOI: 10.1037/0022-006X.69.2.215 [PubMed: 11393599]

Zapolski T, Stairs A, Settles R, Combs J, Smith G. The measurement of dispositions to rash action in children. Assessment. 2010; 17:116-125. DOI: 10.1177/1073191109351372.The [PubMed: 19955108]

Zapolski TC, Smith GT. Pilot study: Implementing a brief DBT skills program in schools to reduce health risk behaviors among early adolescents. J. Sch. Nurs. 2016; Epub ahead of print. doi: $10.1177 / 1059840516673188$

Drug Alcohol Depend. Author manuscript; available in PMC 2018 September 01. 


\section{Highlights}

- $\quad$ Ever smoking increased from $5 \%$ in $5^{\text {th }}$ grade to $27 \%$ in $9^{\text {th }}$ grade in adolescents

- Ever smoking at one wave predicted an increase in urgency at the subsequent wave

- Urgency at one wave increased the likelihood of ever smoking at the subsequent wave

- There exist a reciprocal, longitudinal relationship between ever smoking and urgency 


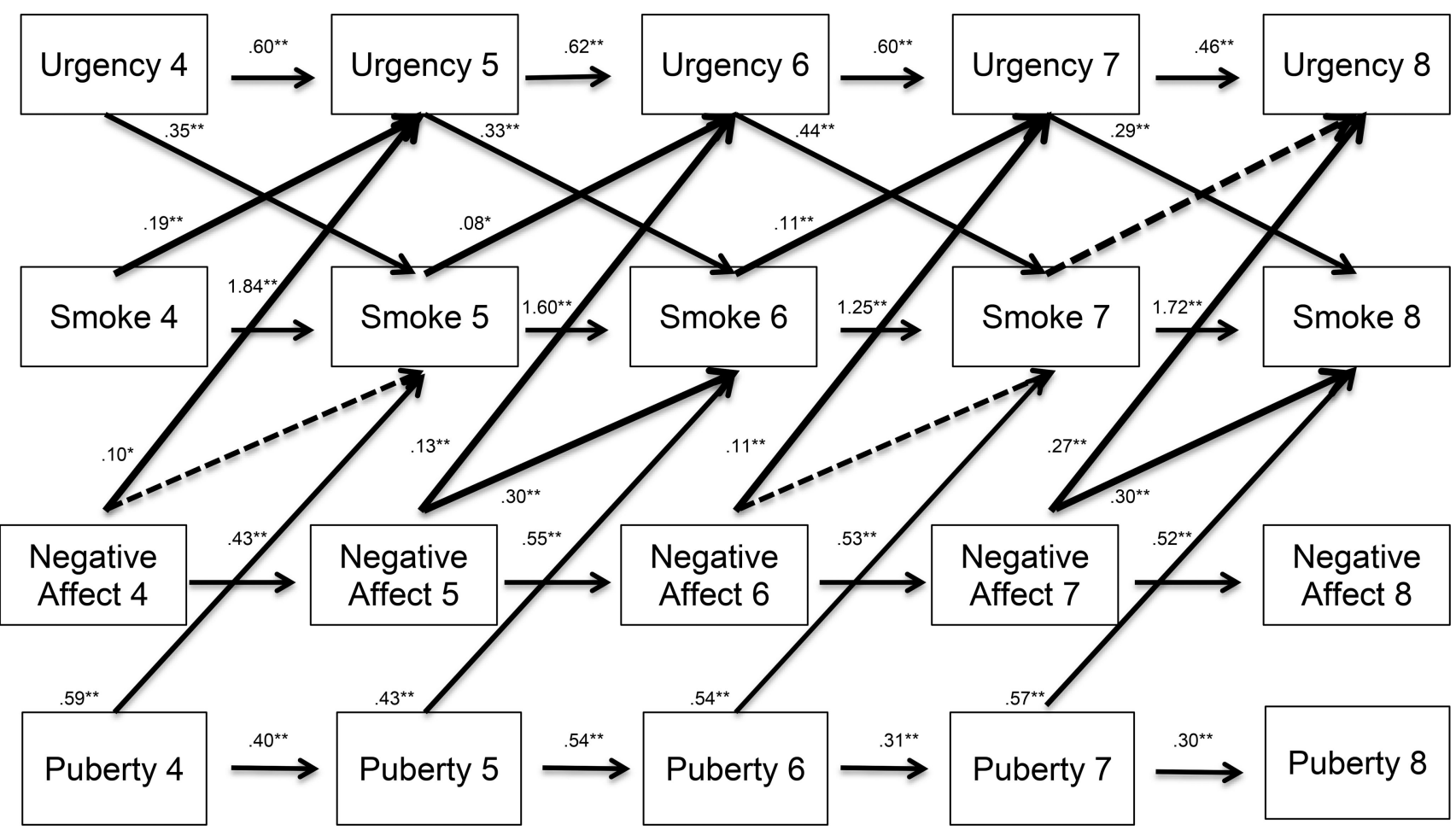

Figure 1. Reciprocal model between smoking and urgency at waves 4 to 8 Note

Note. Horizontal arrows connecting urgency at each wave with urgency at the subsequent waves and ever smoking at each wave with ever smoking at the subsequent waves represent Step 1 of the model, the autoregressive pathways; text above these arrows represents the estimate of the autoregressive effects. Diagonal arrows connecting urgency at each wave with ever smoking at the subsequent wave represent the pathways added at Step 2 of the model; text above these arrows represents the estimate of the pathway from urgency to ever smoking. Diagonal arrows connecting ever smoking at each wave with urgency at the subsequent wave represent the pathways added at Step 3 of the model; text above these arrows represent the estimate of the pathway from ever smoking to urgency. Solid lines indicate significant effects while dashed lines indicate non-significant effect. * $\mathrm{p}<.05 ; * * \mathrm{p}$ $<.01$. 


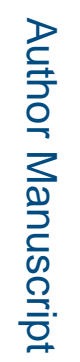

冚

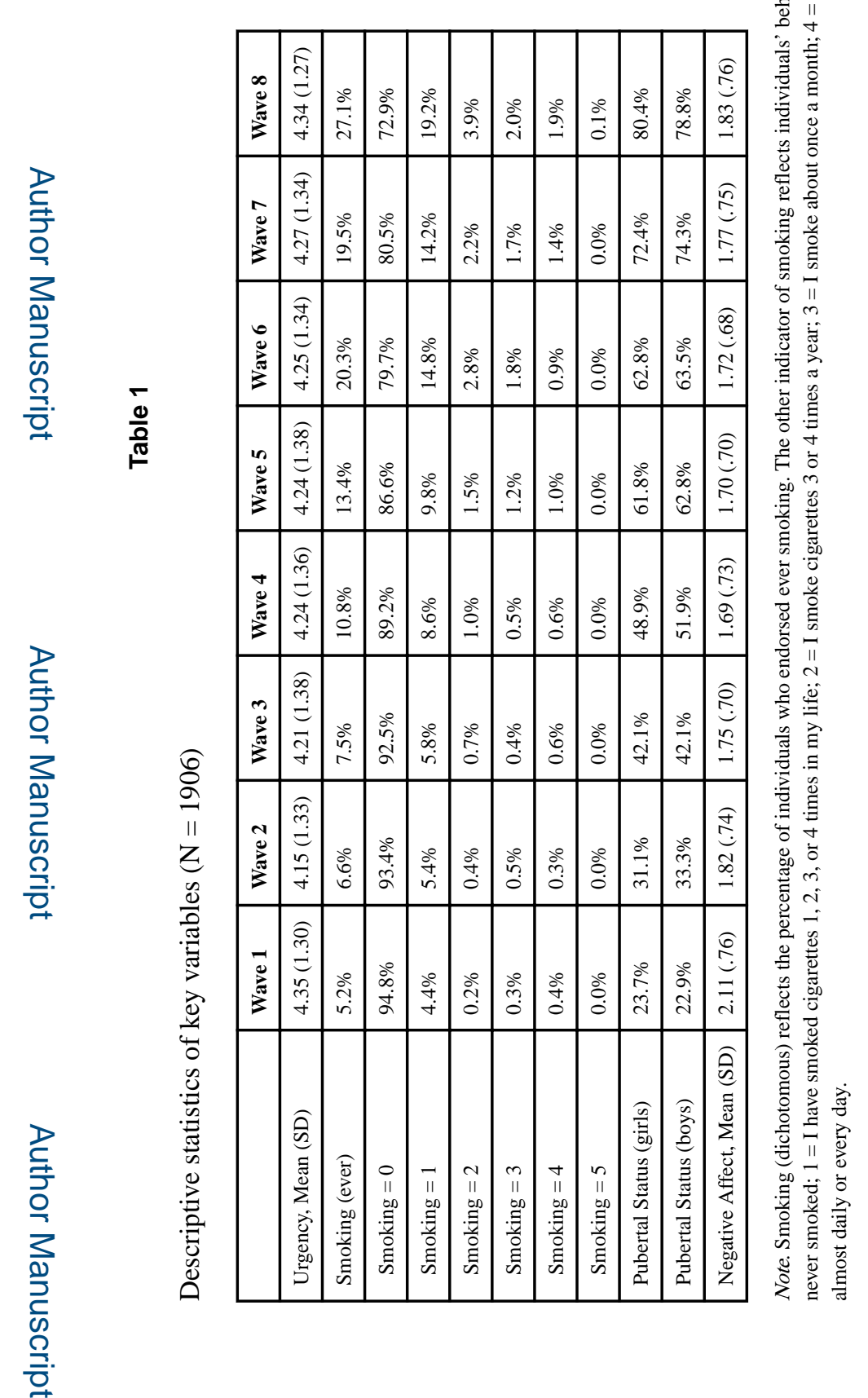

Drug Alcohol Depend. Author manuscript; available in PMC 2018 September 01. 


\begin{tabular}{|c|c|c|c|c|c|c|c|c|c|c|c|c|c|c|c|c|c|c|c|c|c|c|c|}
\hline$\frac{\hat{x}}{z}$ & & & & & & & & & & & & & & & & & & & & & & & \\
\hline $\mid \begin{array}{l}0 \\
z \\
z\end{array}$ & & & & & & & & & & & & & & & & & & & & & & & *o \\
\hline \begin{tabular}{|l|l|}
$n$ \\
$z$
\end{tabular} & & & & & & & & & & & & & & & & & & & & & & ${ }^{*}$ & * \\
\hline$\frac{z}{z}$ & & & & & & & & & & & & & & & & & & & & & * & * ${ }^{\circ}$ & ") \\
\hline$\frac{m}{z}$ & & & & & & & & & & & & & & & & & & & & $\stackrel{*}{*}$ & " & $\stackrel{*^{*}}{\stackrel{\infty}{+} .}$ & $\stackrel{*}{m}$ \\
\hline$\frac{\pi}{z}$ & & & & & & & & & & & & & & & & & & & * & * & * & $\begin{array}{l}{ }^{*} \\
\text { ?. }\end{array}$ & * \\
\hline $\bar{z}$ & & & & & & & & & & & & & & & & & & * & * ${ }_{m}$ & *ัे & * & 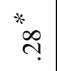 & * \\
\hline \begin{tabular}{|l|}
$\infty$ \\
$\vdots$ \\
5
\end{tabular} & & & & & & & & & & & & & & & & & $\stackrel{*}{*}$ & $\begin{array}{l}* \\
\text { ? } \\
?\end{array}$ & $\stackrel{*}{\infty}$ & 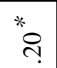 & * ${ }^{*}$ & ${ }^{*}+{ }^{\prime}$ & ${ }^{*}{ }^{2}$ \\
\hline 5 & & & & & & & & & & & & & & & & $\begin{array}{l}{ }^{*} \\
\infty \\
n\end{array}$ & $\begin{array}{ll}* \\
\end{array}$ & $*$ & ${ }^{*} \vec{\top}$ & $\stackrel{*}{\tilde{c}}$ & $\stackrel{*}{*}$ & * ते & * ${ }^{*}$ \\
\hline $\begin{array}{ll}0 \\
\vdots\end{array}$ & & & & & & & & & & & & & & & * & $\stackrel{*}{n}$ & $\stackrel{*}{*}$ & $\stackrel{*}{*} \stackrel{+}{*}$ & ${ }^{*}{ }^{*}$ & * & $\vec{m}$ & * & $\stackrel{*}{*}$ \\
\hline $\begin{array}{ll}0 \\
5\end{array}$ & & & & & & & & & & & & & & *? & " & * & * & ${ }^{*}{ }^{*}$ & ${ }^{*}{ }^{*}{ }^{\circ}$ & 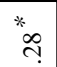 & * & ${ }^{*} \stackrel{m}{m}$ & $\vec{m}$ \\
\hline 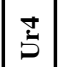 & & & & & & & & & & & & & * & " & $\begin{array}{l}{ }^{*} \\
n_{n}\end{array}$ & $\stackrel{*}{f}$ & \begin{tabular}{l}
$*$ \\
\multirow{2}{*}{} \\
\multirow{2}{*}{}
\end{tabular} & $\begin{array}{ll}* \\
* \\
\\
*\end{array}$ & ${ }^{*}{ }^{*}$ & $\begin{array}{l}*^{*} \\
\text { n? }\end{array}$ & * & *o & * \\
\hline 3 & & & & & & & & & & & & * & $\vec{b}$ & $\stackrel{*}{*}$ & * & $\stackrel{*}{q}$ & $\stackrel{*}{*} \underset{\sim}{*}$ & $\begin{array}{ll}* & \\
* \\
\end{array}$ & * ${ }^{*}$ & * & $\stackrel{*}{*}$ & * & 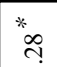 \\
\hline $\mathfrak{\Xi}$ & & & & & & & & & & & ${ }^{*}{ }^{2}$ & * & 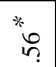 & $\stackrel{*}{*})$ & * & * & $\stackrel{*}{*}$ & $\stackrel{*}{*} \stackrel{0}{m}$ & $\begin{array}{l}* \\
\stackrel{*}{\top}\end{array}$ & $\stackrel{*}{\stackrel{*}{c}}$ & $\stackrel{*}{*}$ & * & $\stackrel{*}{*}$ \\
\hline $\bar{z}$ & & & & & & & & & & * & ${ }^{*}{ }_{n}$ & ${ }^{*}{ }^{\circ} \mathrm{q}$ & * ${ }^{*}$ if & $\stackrel{*}{\stackrel{*}{f}}$ & * $q$. & $\stackrel{*}{*}$ & * ${ }^{*}$ & $\stackrel{*}{*} \underset{\sim}{*}$ & ${ }^{*} \mathrm{~d}$ & ${ }^{*}{ }^{*}$ & ${ }^{*} \varrho$ & ${ }^{*} \cong$ & " \\
\hline$\infty$ & & & & & & & & & $\stackrel{*}{\subsetneq}$ & * & * & "ै & * & * & * ${ }^{*}$ กิ & * & ${ }^{*} \%$ & ${ }^{*} \circ$ & ${ }^{*}=$ & ${ }^{*}{ }^{*}$ & ${ }^{*} \overrightarrow{\mathrm{T}}$ & ${ }^{*} \overrightarrow{\mathrm{T}}$ & * \\
\hline$\hat{n}$ & & & & & & & & * & ${ }^{*} \overrightarrow{\mathrm{C}}$ & * ${ }^{*}$ & ${ }^{*}{ }^{*}$ & $*$ & 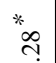 & * & * & * & $\stackrel{*}{\simeq}$ & 8 & ${ }^{*} \subsetneq$ & $\stackrel{*}{=}$ & * $\stackrel{*}{=}$ & $\stackrel{*}{=}$ & ${ }^{*}{ }^{*}$ \\
\hline ஜ & & & & & & & *of & ${ }^{*} \infty$ & * $气$ & * & ${ }^{*} \mathrm{Z}$ & * & $\stackrel{*}{\sim}$ & $\stackrel{*}{\beth}$ & ${ }^{*} \stackrel{d}{\circ}$ & $\stackrel{*}{\infty}$ & 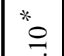 & $\stackrel{*}{ } \stackrel{*}{ }$ & ${ }^{*}$ & ${ }^{*} \mathrm{~g}$ & * & ${ }^{*} \tilde{c}$ & * สి \\
\hline$n$ & & & & & & ${ }^{*}{ }^{*}$ & * & ${ }^{*} q$ & $\stackrel{*}{=}$ & ${ }^{*} \overline{\mathrm{T}}$ & ${ }^{*} \overrightarrow{\mathrm{N}}$ & 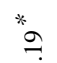 & ${ }^{*}{ }^{*} \mathrm{c}$ & * $\vec{\sim}$ & $\stackrel{*}{\infty}$ & $\stackrel{*}{*}$ & t. & $\stackrel{*}{*}$ & to. & $\stackrel{*}{\simeq}$ & * & $\stackrel{*}{\varrho}$ & $*$ \\
\hline 吉 & & & & & $\frac{*}{n} \cdot$ & ${ }^{*}{ }_{7}$ & * & " & ${ }^{*}{ }^{*}$ & * & ${ }^{*}{ }^{*}$ & * & ${ }^{*}{ }^{*}$ & * & " & $\stackrel{*}{*}$ & $\stackrel{*}{*}$ & $\stackrel{*}{\circ}$ & ${ }^{*} \infty$ & 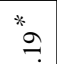 & $\stackrel{*}{\stackrel{*}{?}}$ & $\stackrel{*}{\simeq}$ & * \\
\hline$n$ & & & & *if & ${ }^{*}$ ले & * & 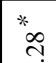 & * ${ }^{*}$ & ${ }^{*} \stackrel{9}{9}$ & $\stackrel{*}{*}$ & $\stackrel{*}{*}$ & 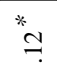 & ${ }^{*}{ }^{*}$ & $\stackrel{*}{\exists}$ & ${ }^{*}=$ & $\stackrel{*}{*}$ & ${ }^{*} \infty$ & ¿ & \& & $*^{*}=$ & * & 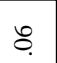 & ${ }^{*} \mathrm{~g}$ \\
\hline$\approx$ & & & * ${ }^{*}$ & * & ${ }^{*}{ }^{*}$ & ${ }^{*}{ }^{*}$ & "ִָ & 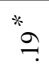 & ${ }^{*}$ & * & * & $\stackrel{*}{*}$ & * & ${ }^{*} \mathrm{~g}$ & * & 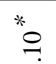 & $\%$ & 8 & to. & ${ }^{*} \infty$ & ${ }^{*} \%$ & 8 & 8 . \\
\hline $\bar{n}$ & & * & $\begin{array}{l}* \\
m \\
m\end{array}$ & * $\stackrel{4}{n}$ & * & 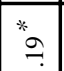 & $\stackrel{*}{*}$ & * & * & * & ${ }^{*}$ & * & 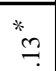 & * & 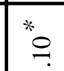 & ${ }^{*}{ }^{\infty}$ & $\begin{array}{l}* \\
* \\
0\end{array}$ & 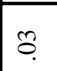 & $\bar{\sigma}$ & $\begin{array}{l}* \\
\infty \\
0\end{array}$ & ${ }^{*} 8$ & * & * \\
\hline & $\bar{n}$ & $\tilde{n}$ & $\ddot{n}$ & $\dot{\vec{n}}$ & $n$ & $\begin{array}{l}\dot{0} \\
i n\end{array}$ & is & $\begin{array}{l}\infty \\
\sim\end{array}$ & $\overline{5}$ & 焉 & 5 & $\begin{array}{l} \\
5 \\
\end{array}$ & $\begin{array}{l}n \\
5 \\
5\end{array}$ & $\begin{array}{l}0 \\
5\end{array}$ & $\hat{5}$ & $\begin{array}{l}\infty \\
5 \\
5\end{array}$ & $\bar{z}$ & $\frac{\pi}{z}$ & $\frac{m}{z}$ & 菨 & $\frac{n}{z}$ & $\frac{⿱}{1}$ & 齐 \\
\hline
\end{tabular}




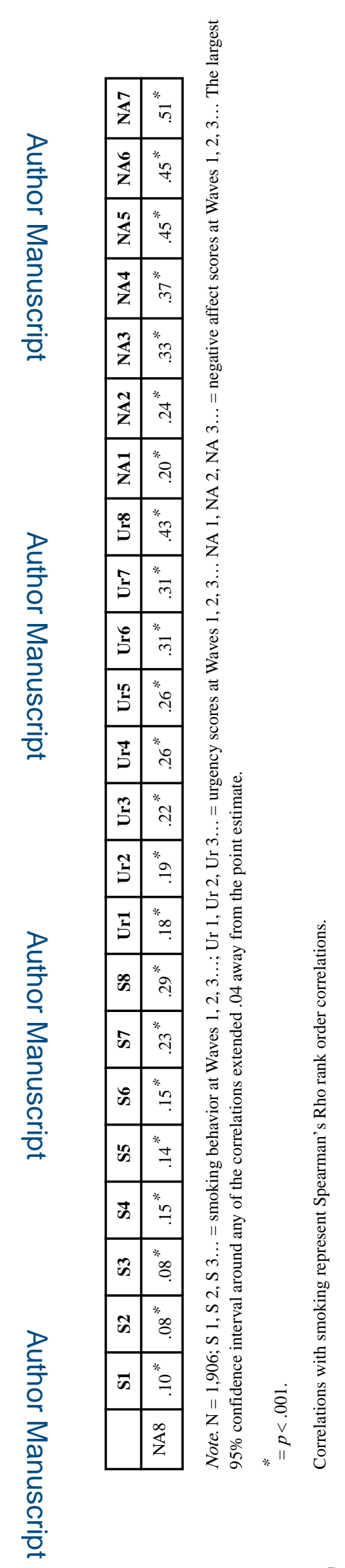

Drug Alcohol Depend. Author manuscript; available in PMC 2018 September 01. 